\section{PERCEPÇÃO DOS LICENCIANDOS EM QUÍMICA SOBRE A APLICAÇÃO DO JOGO DA QUÍMICA II}

\author{
Perception of Chemistry Graduates on the Application of the Chemistry Game II
}

Percepción de los licenciados en química sobre la aplicación del Juego de la Química II

\section{Resumo}

A presente pesquisa apresenta a elaboração de um jogo didático, o Jogo da Química II, inspirado em um conjunto de jogos comerciais de amplo sucesso, como também a análise da percepção dos alunos de uma turma do quarto período da Licenciatura em Química da Universidade Federal Rural de Pernambuco sobre a aplicação desse jogo como instrumento para o ensino de conceitos químicos. A aplicação foi vídeo-gravada e logo após a aplicação foram realizadas entrevistas com quatro alunos que participaram da atividade. Para análise do jogo foram utilizados os critérios de validação propostos por Novak e Souza, a saber: interação entre os jogadores, dimensão da aprendizagem, jogabilidade, aplicabilidade, desafio, limitação de espaço e tempo e criatividade. Os resultados obtidos mostram que o Jogo da Química II passou pelos critérios de validação na aplicação e que os licenciandos avaliaram positivamente o mesmo, podendo assim ser inserido como uma alternativa pedagógica para o ensino de química.

Palavras-Chave: Jogos Didáticos; Jogo da Química II; Ensino de Química.

\section{Abstract}

This research presents the elaboration of a didactic game, the "Game of Chemistry II", inspired by a set of commercial games of great success, as well as the analysis of the perception of a group of students on the fourth semester of the Chemistry Licenciate Degree of the Universidade Federal Rural de Pernambuco about the application of this game as an instrument for the teaching of chemical concepts. The application was video-recorded and right after it, interviews were conducted with four students who participated in the activity. For the analysis of the game, the validation criteria proposed by Novak and Souza, namely: interaction among the players, dimension of learning, gameplay, applicability, challenge, limitation of space and time and creativity. The obtained results show that the Game of Chemistry II passed the validation criteria in the application and that the undergraduates positively rated the game, wich is be able to be inserted as a pedagogical alternative for the teaching of chemistry.

Keywords: Didactic Games; Game of Chemistry II; Chemistry Teaching.

\section{Resumen}

La presente investigación presenta la elaboración de un juego didáctico, el Juego de la Química II, inspirado en un conjunto de juegos comerciales de amplio éxito, así como el análisis de la percepción de los alumnos de una clase del cuarto período de la Licenciatura en Química de la Universidad Federal Rural De Pernambuco sobre la aplicación de ese juego como instrumento para la enseñanza de conceptos químicos. La aplicación fue video-grabada y luego de la aplicación se realizaron entrevistas con cuatro alumnos que participaron en la actividad. Para el análisis del juego se utilizaron los criterios de validación propuestos por Novak y Souza, a saber: interacción entre los jugadores, dimensión del aprendizaje, jugabilidad, aplicabilidad, desafío, limitación de espacio y tiempo y creatividad. Los resultados obtenidos muestran que el Juego de la Química II pasó por los criterios de validación en la aplicación y que los licenciandos evaluaron positivamente el mismo, pudiendo ser insertado como una alternativa pedagógica para la enseñanza de química. Palabras clave: Juegos Didácticos; Juego de la Química II; Enseñanza de la Química.
AUTORES:

CARLA MARIA DE JESUS DA

SILVA ${ }^{1}$

ORCID 0000-0003-4120-7895

${ }^{1}$ Universidade Federal Rural de Pernambuco (UFRPE)

\begin{tabular}{r} 
HICCARO CARLOS \\
RODRIGUES DE ALMEIDA ${ }^{2}$ \\
ORCID 0000-0001-7897-6060 \\
Universidade Federal de \\
Pernambuco (UFPE) \\
\hline JOSEANE DA CONCEIÇÃO \\
SOARES DA SILVA ${ }^{3}$ \\
ORCiD 0000-0003-4864-9135 \\
3Universidade Federal Rural \\
de Pernambuco (UFRPE) \\
\hline JOSÉ EUZEBIO SIMÕES \\
NETO 4 \\
ORCID 0000-0002-5599-5047 \\
4Universidade Federal Rural \\
de Pernambuco (UFRPE)
\end{tabular}

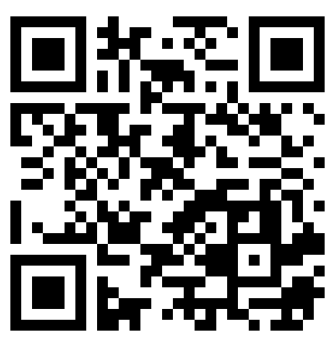

Para citar este artigo:

SIMÕES NETO, J. E. et al. Percepção dos

Licenciandos em

Química sobre a

aplicação do Jogo da

Química II. Revista

Eletrônica Ludus

Scientiae, Foz do Iguaçu,

v. 01, n. 01, p. 126-141, jan./jul. 2017. 


\section{INTRODUÇÃO}

O estudo da Química é fundamental para a formação dos estudantes, pois é um ramo da ciência que estuda a matéria, suas propriedades, constituição, transformações e a energia envolvida em processos, estando presente em diversas atividades que realizamos cotidianamente, como cozinhar, cuidar dos cabelos, tomar banho, escovar os dentes. Todavia, diversas pesquisas mostram que, ao longo do processo educacional, os alunos manifestam dificuldades de aprendizagem de conceitos químicos (QUADROS et al., 2011; SANTOS et al., 2013; MACHADO e CAVALCANTI, 2015). Entendemos que para os alunos a química não é uma disciplina fácil, pelas características abstratas do conhecimento químico e também pela opção recorrente do ensino de química a partir de uma abordagem tradicional, desvinculada da realidade dos alunos, culminando em aulas monótonas, com muitas fórmulas e nomenclaturas complicadas, que terminam por direcionar a falta de interesse pela química, dificultando assim a aprendizagem.

Para Soares, Okumura e Cavalheiro (2003) o desenvolvimento de estratégias modernas e simples, como a utilização de experimentos, jogos e outros recursos didáticos, é recomendado para dinamizar os processos de ensino e aprendizagem em Química. Ainda, os Parâmetros Curriculares Nacionais - PCNs (BRASIL, 1997) sugerem aos professores que busquem adotar diferentes estratégias, tais como experimentação, simulações, debates e jogos, pois poderão facilitar a aprendizagem dos conceitos químicos. Destacamos nessa pesquisa os jogos didáticos, que, segundo Kishimoto (1994) devem possuir duas funções: a lúdica e a educativa. Elas devem estar em equilíbrio, pois se a função lúdica prevalecer, não passará de um jogo e se a função educativa for predominante, o instrumento será apenas um material didático. Esses ainda se caracterizam por alguns elementos, como por exemplo: o prazer e o esforço espontâneo, além de integrarem as várias dimensões do aluno, como a afetividade e o trabalho em grupo.

O potencial dos jogos está relacionado, entre outros fatores, a necessidade de brincar das pessoas. Para Santos (1997), o lúdico é uma necessidade do ser humano, em qualquer idade, mas não pode ser vista apenas como diversão. $\mathrm{O}$ desenvolvimento do aspecto lúdico facilita a aprendizagem, $o$ desenvolvimento pessoal, social e cultural, colabora para uma boa saúde mental, prepara para um estado interior fértil, facilita os processos de socialização, comunicação, expressão e construção do conhecimento.

Os jogos didáticos são indicados como um tipo de recurso didático educativo a ser utilizados em momentos distintos, como na apresentação de um conteúdo, ilustração de aspectos relevantes ao conteúdo, como revisão ou síntese de conceitos importantes e avaliação dos conhecimentos construídos (CUNHA, 2004). Dessa forma, a aplicação de jogos didáticos no ensino da Química vai se apresentar como um recurso que pode auxiliar nos processos de ensino e aprendizagem.

\section{O que são Jogos?}

Os jogos têm aparecido em várias épocas e em diversos lugares, com destaque para a Grécia antiga, berço do modo de pensar predominante no ocidente, onde grandes pensadores evidenciavam a importância da atividade lúdica no processo de formação da criança. Platão (427-347 a.C.) defendeu o valor e a importância de se aprender brincando, sendo necessário estimular tal prática para formação da personalidade. Para Aristóteles (385-322 a.C.), além de preparar a criança para a vida adulta, o jogo funcionava de uma forma que a percepção comece a se voltar diante do mundo real.

A maioria das pessoas associa jogo como atividade física ou mental que está relacionada a passatempo ou divertimento, tais como jogos com bola, corridas, jogos de tabuleiro, jogo de cartas, ou, mais recentemente, à videogames, jogos computacionais e jogos desenvolvidos para aparelhos celulares. No geral, os jogos estão associados a atividades de lazer, como também a atividades mentais que ajudam no desenvolvimento do raciocínio. Todas as atividades relacionadas a jogos têm uma 
característica importante, o estabelecimento de regras previamente combinadas que é necessário obedecer.

A definição elaborada por Huizinga (200o) está presente na maioria das pesquisas a respeito de jogos, e diz que:

O jogo é uma atividade ou ocupação voluntária, exercida dentro de certos e determinados limites de tempo e de espaço, segundo regras livremente consentidas, mas absolutamente obrigatórias; dotado de um fim em si mesmo, acompanhado de um sentimento de tensão e de alegria e de uma consciência de ser diferente da vida cotidiana (HUIZINGA, 2000, p. 33).

Então, o jogo é uma atividade voluntária e o jogador se dispõe a jogar de forma consciente, obedecendo às regras e tempo da atividade, levando-o ao seu objetivo. O jogo por si só deve trazer satisfação e alegria, além de fazer com que a pessoa ao jogar, esqueça, pelo tempo que durar o jogo, de sua vida real. Segundo Soares (2008), o jogo é:

[...] o resultado de interações linguísticas diversas em termos de características e ações lúdicas, ou seja, atividades lúdicas que implicam no prazer, no divertimento, na liberdade e na voluntariedade, que contenham um sistema de regras claras e explícitas e que tenham um lugar delimitado onde possa agir: um espaço ou um brinquedo" (SOARES, 2008, p.4).

Diante de todas as características apresentadas, quando um jogo é utilizado para o ensino e aprendizagem de conceitos, ele possui características distintas, embora sem perder a maior parte das características dos jogos comerciais e é classificado como um jogo didático, que discutiremos a seguir.

\section{Os Jogos Didáticos}

Os jogos didáticos podem ser entendidos como uma dentre as diversas ferramentas inovadoras no campo da educação, e possuem potencial para o desenvolvimento de competências e habilidades que são fundamentais para a aprendizagem de conceitos científicos, e podem, dessa forma, aumentar a motivação dos alunos durante o processo de aprendizagem. Segundo Santana (2008):

O lúdico é integrador de várias dimensões do aluno, como a afetividade, o trabalho em grupo e das relações com regras pré-definidas, promovendo a construção do conhecimento cognitivo, físico e social (SANTANA, 2008, p. 5).

Existem vários tipos de jogos didáticos, e o professor precisa identificar qual é o mais adequado para ser trabalhado em sala de aula. Reconhecendo a importância da sua utilização correta para que venha ajudar o aluno. A depender do jogo, o aluno terá oportunidade de aprimorar seus conhecimentos, desenvolver a inteligência, enriquecer a linguagem oral e escrita, o que contribui para a participação ativa, criativa e crítica no processo de aprendizagem (ALMEIDA, 2003).

Um jogo didático é definido pelo equilíbrio existente entre duas funções, a função lúdica, aquela que propicia diversão e prazer, e a função educativa, relacionada ao uso dos jogos com a finalidade de ensinar qualquer coisa ao jogador (SOARES, 2016). Entender essa necessidade de equilíbrio é a melhor maneira de aplicar o jogo para que exista a diversão (ao cumprir a função lúdica e evitar que o material seja puramente didático) e a aprendizagem (ao cumprir a função educativa) são os desafios maiores que um professor enfrenta, na utilização dos jogos didáticos. Ainda em Soares (2016), encontramos aspectos que, podem auxiliar a minimizar o paradoxo do jogo educativo em uma aplicação didática. São propostas duas ações: 
(i) Deve haver consciência do aluno que o jogo utilizado em sala de aula é educativo - ou seja, não deve ser escondido que a intenção do jogo vai além da diversão, é também a aprendizagem de um conceito em destaque.

(ii) Deve haver liberdade e voluntariedade em sala de aula - ou seja, o ato de jogar deve ser espontâneo, com o professor encarando a utilização do jogo como um convite, e não uma obrigação, o que tornaria o jogo algo obrigatório e diminuiria a contribuição da função lúdica da proposta.

Assim, durante a utilização dos jogos didáticos, o professor deve ser capaz de gerar um ambiente favorável ao trabalho em equipe e à manifestação da criatividade dos seus alunos por intermédio de pequenos desafios que permitam avanços graduais, mas sempre com o constante cuidado de garantir o equilíbrio entre as funções lúdica e educativa.

Por fim, é importante considerar que o jogo didático favorece o aprendizado através do erro. Segundo Kishimoto (1994), o jogo permite estimular a exploração em busca de respostas, sem constranger o aluno quando este erra. Desse modo, quando usado como recurso didático, esse também poderá auxiliar o professor na análise dos erros dos alunos, servindo como um sistematizador dos conceitos que foram abordados/trabalhados durante o jogo.

\section{Jogos Didáticos no Ensino da Química}

Estudos como Soares $(2008,2016)$ e Simões Neto et al. (2016) constataram a importância da utilização de jogos e atividades lúdicas para o Ensino de Química, buscando desafios e fazendo com que essas atividades se tornem viáveis e possam auxiliar no processo de aprendizagem dos conceitos químicos.

Como já expomos, o Ensino de Química é, em geral, bastante associado a pedagogia tradicional, baseada na transmissão das informações, na simples memorização e repetição de nomes, fórmulas e cálculos, totalmente desvinculados do cotidiano e da realidade em que os alunos se encontram. A Química, nessa situação, torna-se uma disciplina monótona, fazendo com que os próprios estudantes questionem o motivo pelo qual esses conceitos lhes são ensinados. Por outro lado, quando o estudo da Química faculta aos alunos o desenvolvimento paulatino de uma visão crítica do mundo que os cerca, seu interesse pelo assunto aumenta, pois lhes são dadas condições de perceber e discutir situações relacionadas a problemas sociais e ambientais do meio em que estão inseridos, contribuindo para a possível intervenção e resolução dos mesmos (SANTANA, 2006).

Cunha (2004) destaca que os jogos são um importante recurso para as aulas de química, no sentido de servir como um reabilitador da aprendizagem mediante a experiência e a atividade dos estudantes. Além disso, permitem experiências importantes não só no campo do conhecimento, mas desenvolvem diferentes habilidades especialmente também no campo afetivo e social do estudante. Essas atividades, quando bem exploradas e desenvolvidas, oportunizam a interlocução de saberes, a socialização e o desenvolvimento pessoal, social e cognitivo. O jogo, além de ser uma fonte de prazer e descoberta, contribui no processo de construção do conhecimento (MELO, 2005, p. 129).

É muito importante deixar claro que os jogos didáticos no ensino de química têm como função a familiarização com a linguagem química e não de memorização de nomes, fórmulas e conceitos. Sua finalidade é proporcionar um conhecimento mais amplo em relação às representações utilizadas nessa ciência, principalmente quando a mesma busca desenvolver no estudante a capacidade de entendimento dos conceitos químicos. Tanto os conceitos trabalhados no jogo quanto a sua dinâmica lúdica devem ser considerados para que se possa identificar e usar o jogo adequado para os fins pedagógicos que se busca atingir. 
Baseado na potencialidade dos jogos didáticos como estratégia didática para aulas de química, é que propomos o Jogo da Química II, inspirado no Jogo da Química original, que por sua vez foi idealizado como síntese de desafios e atividade de jogos comerciais de sucesso.

Diante do exposto, os objetivos desse trabalho são:

(i) Elaborar o jogo didático intitulado “Jogo da Química II”, inspirado no Jogo da Química, estabelecendo suas regras.

(ii) Analisar as percepções de licenciandos em química sobre a aplicação do Jogo da Química II como instrumento para o ensino e a aprendizagem de conceitos químicos.

\section{METODOLOGIA}

A pesquisa tem caráter qualitativo e foi desenvolvida em duas etapas maiores, a primeira relacionada a elaboração do Jogo da Química II, e a segunda relativa a aplicação do jogo em uma turma de licenciandos em Química. Ainda, elaboramos uma metodologia para análise dos dados obtidos na pesquisa, apresentada ao final da seção.

\section{Elaboração do Jogo da Química II}

A elaboração do jogo foi feita a partir das informações acerca do Jogo da Química (ALMEIDA e SIMÕES NETO, 2010), com algumas modificações realizadas com base na literatura sobre jogos didáticos e os conteúdos específicos envolvidos no jogo. Sobre o Jogo da Química original:

O Jogo da Química é um jogo de tabuleiro, jogado em disputa de duas a quatro equipes, é constituído de um tabuleiro de sessenta casas, de quatro cores diferentes (verde, azul, vermelho e amarelo), quatro peões das mesmas cores citadas, um dado e um conjuntos de cento e noventa cartas, divididas em três categorias: "perguntas objetivas" (com quatro opções), "desenhar para conquistar" (em que a equipe tenta adivinhar o que um dos membros está desenhando) e "siga a pista" (uma série de cinco pistas para a equipe descobrir o nome do cientista, do material de laboratório ou elemento químico em questão) (ALMEIDA e SIMÕES NETO, 2010).

De início, discutimos o nome do jogo (que deveria ser associado à proposta original), o modelo do tabuleiro, as perguntas e informações colocadas nas cartas do jogo, consideradas uma predefinição importante, pois se o jogo não fosse bem recebido pelos alunos poderia apresentar resultados insatisfatórios.

As cartas do jogo foram estruturadas a partir de conteúdos de química geral, química orgânica, físico-química e história da química e distribuídas em diferentes categorias representadas em três cores: verde, azul e amarelo, correspondendo as diferentes modalidades de desafio, em associação direta as cores das casas no tabuleiro. Foram valorizados os temas de difícil visualização ou que são comumente citados em literatura como problemáticos da química geral, química orgânica, físicoquímica, que necessitam abstração para entendimento, como átomos, moléculas, reações químicas, radioatividade, íons em solução, entre outros, além de incluir elementos da história da química.

Ao longo do processo de elaboração o Jogo da Química II, algumas alterações foram sendo realizadas, como por exemplo, a substituição de algumas perguntas e cartas de perfil. Para a construção do tabuleiro e de suas respectivas cartas foi utilizado o programa CorelDRAW Graphics Suite X8. O tabuleiro foi reorganizado até assumir o desenho final, atrativo para o jogador e inspirado no Jogo Banco Imobiliário (ou Monopoly, da Hasbro).

A versão final foi impressa em tabuleiro em PVC, no formato de banner, tendo $45 \mathrm{~cm}$ por 45 $\mathrm{cm}$. As 75 cartas foram impressas em papel cartão, medindo 9x6 cm cada, sendo destas 30 na cor verde 
("perguntas objetivas"), 30 cartas na cor azul ("desenhar para conquistar") e 15 cartas na cor amarela (“siga a pista”).

\section{Coleta de Dados - Aplicação do Jogo da Química II e Entrevistas}

A aplicação do jogo ocorreu em uma turma da disciplina Prática Pedagógica no Ensino de Química I, componente curricular obrigatório do curso de Licenciatura em Química da Universidade Federal Rural de Pernambuco (UFRPE), oferecida regularmente no $4^{\circ}$ período do curso. Trabalhamos com a turma de 2016.2, no turno da tarde, com quinze alunos, divididos em quatro grupos, que participaram da pesquisa voluntariamente. A aplicação durou duas horas e 10 minutos, e foi realizada em horário de aula, com anuência e participação do professor da disciplina.

Os procedimentos para coleta dos dados dessa pesquisa envolveram 2 etapas: a primeira foi a aplicação do Jogo da Química II e a segunda etapa constituiu em uma entrevista, a qual nos permitiu fazer uma análise das percepções dos professores em formação inicial acerca do jogo proposto.

Inicialmente foi apresentado aos alunos o objetivo da atividade. Todos foram informados que a ideia do Jogo da Química II era contribuir para o processo de ensino e aprendizagem dos conceitos químicos, permitindo que os alunos revisassem e exercitassem os assuntos que são abordados no Ensino Médio. Os grupos de trabalho foram selecionados pelo professor da disciplina e foi estabelecido antes do início do jogo que seria dada apenas uma volta no tabuleiro.

O Jogo da Química II foi apresentado juntamente com suas regras, presentes no manual, pelo professor da disciplina, em voz alta e esclarecendo as dúvidas. Em acordo com cada equipe, os estudantes escolheram pinos de cores diferentes para representar a sua equipe, sendo a equipe que alcançou o maior número do dado, aquela que iniciaria o jogo, com a sequência de jogadas em sentido horário. Logo após a escolha da sequência dos grupos, a equipe que tirou o maior número do dado jogou-o novamente e andou no tabuleiro o número de casas correspondentes ao número do dado. A cada rodada um aluno da equipe jogava o dado. Ao caminhar no tabuleiro, os jogadores puxariam uma carta da mesma cor da casa em que pararam, no tabuleiro.

Cada equipe possuía um limite de tempo determinado na ampulheta, dependendo das casas que caíam, para discutir, trabalhar com as informações e responder as perguntas. Para cada resposta certa a equipe ganhava o direito de jogar o dado na próxima rodada. No caso das respostas erradas, a equipe permanecia na mesma casa e ganhava um disco, impossibilitando a equipe jogar o dado na próxima rodada, conforme as regras do jogo.

Ao término do jogo foram selecionados quatro alunos, um de cada equipe, para uma entrevista individual. As perguntas que compunham a entrevista estão colocadas no Quadro o1.

Quadro 1 - Perguntas da Entrevista.

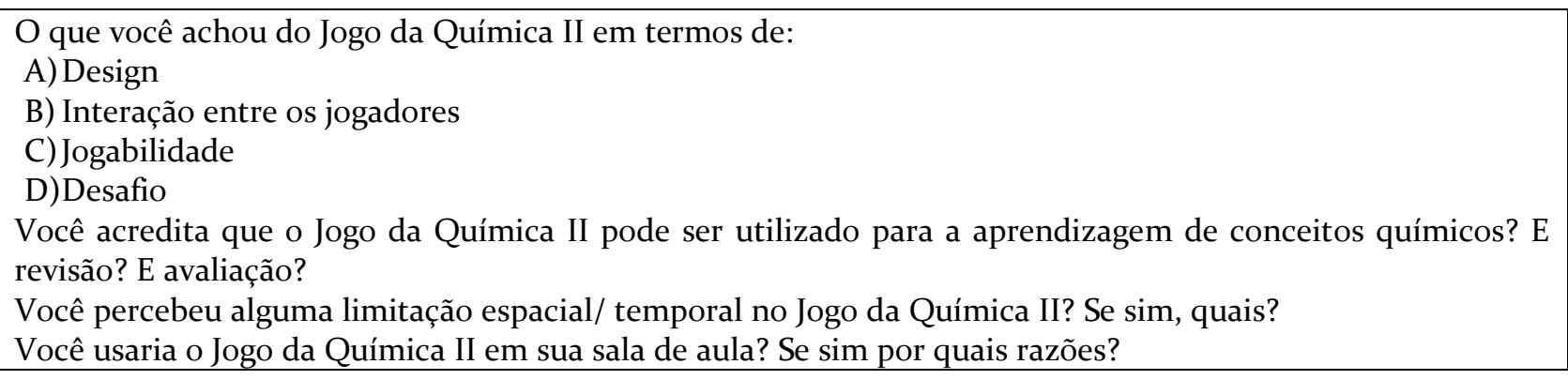

A aplicação do jogo foi gravada em vídeo, enquanto que as entrevistas foram gravadas somente em áudio, nos dois casos, com a autorização dos estudantes envolvidos. 


\section{Análise dos Dados}

Os dados recolhidos durante a aplicação do jogo e também a partir das entrevistas foram analisados buscando identificar, em ambos os momentos, percepções dos estudantes envolvidos na atividade para validar o Jogo da Química II. Assim, a partir de dados selecionados na aplicação e das respostas a entrevista, utilizamos alguns critérios elencados por Nóvak e Souza (2008), a partir da leitura realizada por Simões Neto et al. (2016) e que está apresentada e justificada no quadro 02:

Quadro 2 - Critérios de Validação Utilizados na Análise dos Dados.

\begin{tabular}{|c|l|}
\hline $\begin{array}{c}\text { CRITÉRIO DE } \\
\text { VALIDAÇÃO }\end{array}$ & \multicolumn{1}{c|}{ JUSTIFICATIVA } \\
\hline $\begin{array}{c}\text { Interação entre os } \\
\text { jogadores }\end{array}$ & $\begin{array}{l}\text { O jogo apresenta potencialidade de cooperação e/ou competição entre os } \\
\text { participantes? }\end{array}$ \\
\hline $\begin{array}{c}\text { Dimensão da } \\
\text { aprendizagem }\end{array}$ & $\begin{array}{l}\text { O jogo visa a aprendizagem? O jogo pode ser utilizado para testar conhecimentos } \\
\text { construídos? O jogo direciona a memorização de dados ou fatos de maneira } \\
\text { adequada? }\end{array}$ \\
\hline Jogabilidade & A jogabilidade do jogo é relativamente simples e propicia a imersão necessária? \\
\hline Aplicabilidade & O jogo permite variações na aplicação? \\
\hline Poder de desafio & $\begin{array}{l}\text { O jogo desafia o jogador e se apresenta como uma situação que busca o } \\
\text { engajamento dos estudantes? }\end{array}$ \\
\hline $\begin{array}{c}\text { Limitação de espaço e } \\
\text { tempo }\end{array}$ & $\begin{array}{l}\text { O jogo apresenta limitação de espaço adequadas para a sala de aula? O jogo pode } \\
\text { ser aplicado em tempo adequado para as aulas? }\end{array}$ \\
\hline Criatividade & O jogo considera situações em que a criatividade seja considerada? \\
\hline
\end{tabular}

\section{RESULTADOS E DISCUSSÃO}

Apresentaremos os resultados e a discussão em três tópicos, a saber: O Jogo da Química II, Aplicação do Jogo da Química II e Entrevista com os Estudantes.

\section{O Jogo da Química II}

O Jogo da Química II é uma adaptação do Jogo da Química (ALMEIDA e SIMÕES NETO, 2010), como proposta de atividade lúdica, tendo como função principal servir como instrumento para professores do Ensino Médio, atuando como agente motivador da busca pelo conhecimento químico, utilizando uma abordagem lúdica para atrair o interesse dos alunos e tornar o aprendizado mais divertido. O Jogo da Química foi elaborado, mas não foi construído, se tornando uma proposta incompleta.

Ao revisitar a ideia original, decidimos modificar algumas partes do jogo, e, por isso, decidimos chamar o jogo apresentado nesse artigo de Jogo da Química II, que foi desenvolvido com base no Jogo da Química, que por sua vez foi pensado como adaptação de três jogos comerciais bastante difundidos: Perfil, Master e Imagem e Ação, todos da Grow, com diversas adaptações das regras dos jogos tradicionais, buscando elaborar um jogo didático inovador para o ensino de química. É um jogo de tabuleiro, no qual entram em disputa de duas a quatro equipes (a depender da quantidade de alunos), que respondem perguntas, tentam adivinhar o nome de cientistas e/ou filósofos, objeto ou conceito a partir da apresentação de um perfil ou tentam acertar o nome do objeto ou conceito que está sendo desenhado.

O tabuleiro foi desenhado contendo uma trilha de 44 casas, sendo estas divididas em: uma casa preta, indicando partida e chegada, quinze casas verdes, que indicam que os jogadores devem puxar cartas de "perguntas objetivas", dezessete casas azuis, que indicam que os jogadores devem puxar cartas "desenhar para conquistar", sete casas amarelas, que indicam que os jogadores devem puxar 
cartas "siga a pista" e quatro casas vermelhas, com vantagens ou punições que devem ser consideradas pelos jogadores. A figura o1 mostra o tabuleiro do jogo:

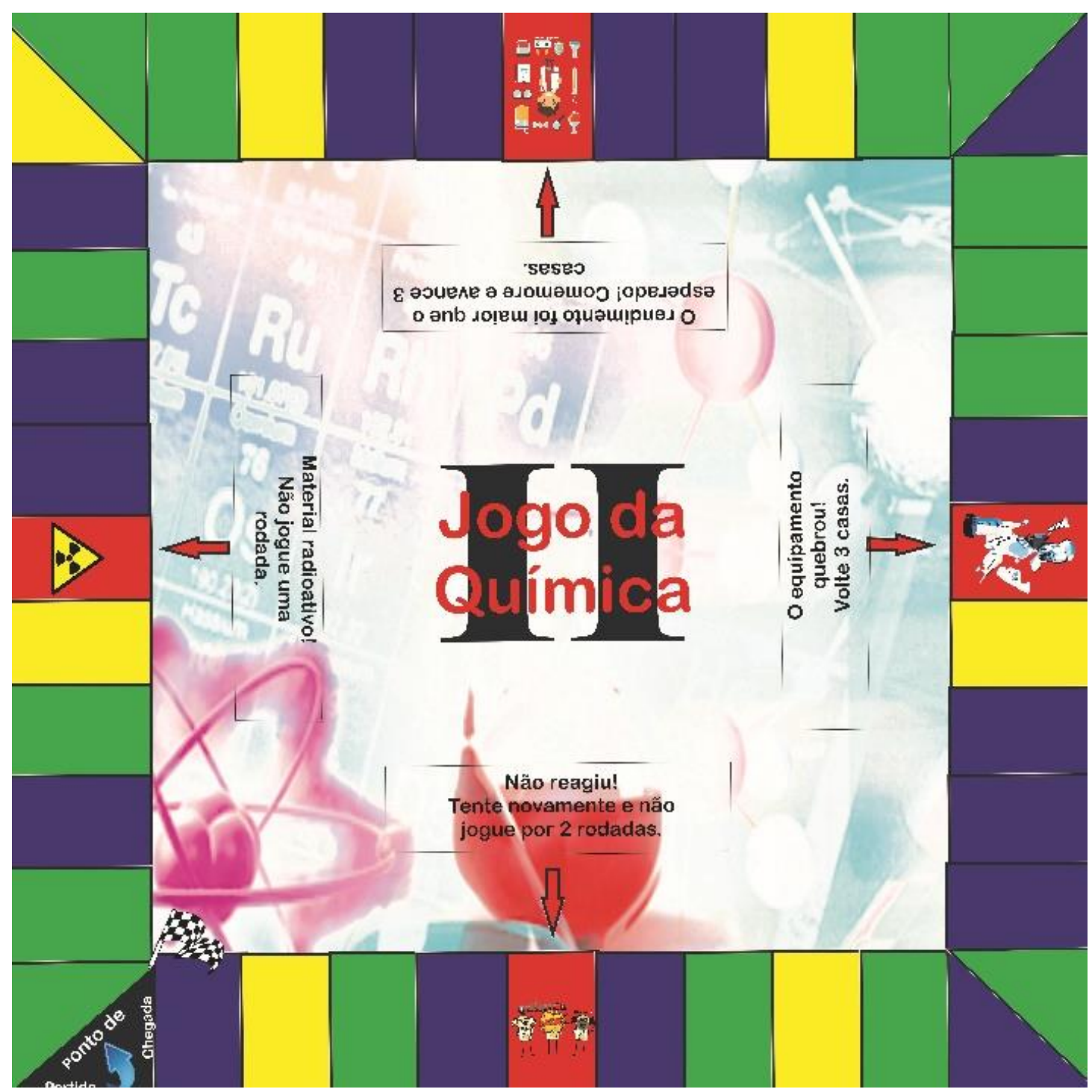

Figura 1 - Tabuleiro do Jogo da Química II.

O objetivo das equipes é levar o seu peão a última casa do tabuleiro e assim vencer o jogo. Para isso, as cartas devem ser puxadas e os desafios cumpridos no menor número de rodadas possível. $\mathrm{O}$ verso das cartas é mostrado na figura 02: 


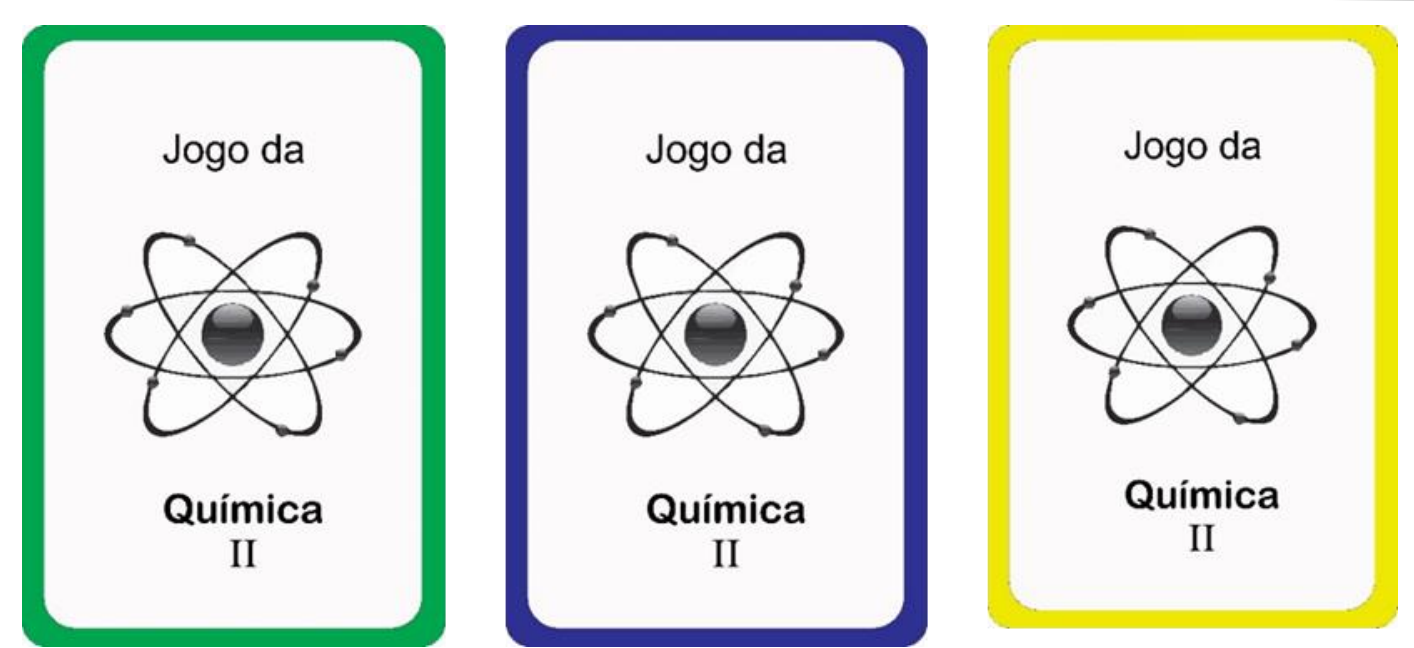

Figura 2 - Frente das cartas de desafios - verde ("perguntas objetivas"), azul (“desenhar para conquistar") e amarelas ("siga a pista").

As cartas verdes possuem "perguntas objetivas" sobre química, com quatro opções de resposta, sendo apenas uma correta. Um dos componentes da equipe faz a pergunta e os outros devem responder no tempo determinado pela ampulheta. Se acertarem, está livre para na próxima rodada jogar novamente o dado e andar pela trilha. Se errar, recebe um disco e na próxima rodada novamente puxam outra carta verde. A equipe só poderá se movimentar quando acertar a pergunta e devolver o disco.

As cartas azuis possuem uma palavra, que pode ser um conceito, um material de laboratório ou um processo, que deve ser desenhado por um componente do grupo e os demais deverão interpretar o que está sendo desenhado, no tempo determinado pela ampulheta. Quem estiver desenhando não pode falar e nem escrever, mas pode fazer gestos. Se o grupo acertar, está livre para na próxima rodada jogar novamente o dado e andar pela trilha. Se errar, recebe um disco e na jogada seguinte novamente puxa uma outra carta azul. A equipe só pode se movimentar quando acertar um desenho e devolver o disco.

Por fim, as cartas amarelas, do tipo "siga a pista". Um dos componentes da equipe puxa a carta e outro componente joga o dado. O número indicado pelo dado corresponde a pista que deverá ser lida. Cada carta possui seis pistas sobre um cientista, conceito ou material. A equipe deverá andar pela trilha quando acertar a resposta: quatro casas, se acertar na primeira pista, três casas, se acertar na segunda pista, duas casas, se acertar na terceira pista e uma casa, para se acertar na quarta pista. A equipe que cair em uma casa amarela não joga o dado na próxima rodada, devendo respeitar as recomendações da casa que cair. A figura 3 mostra um exemplo de cada tipo de carta. 

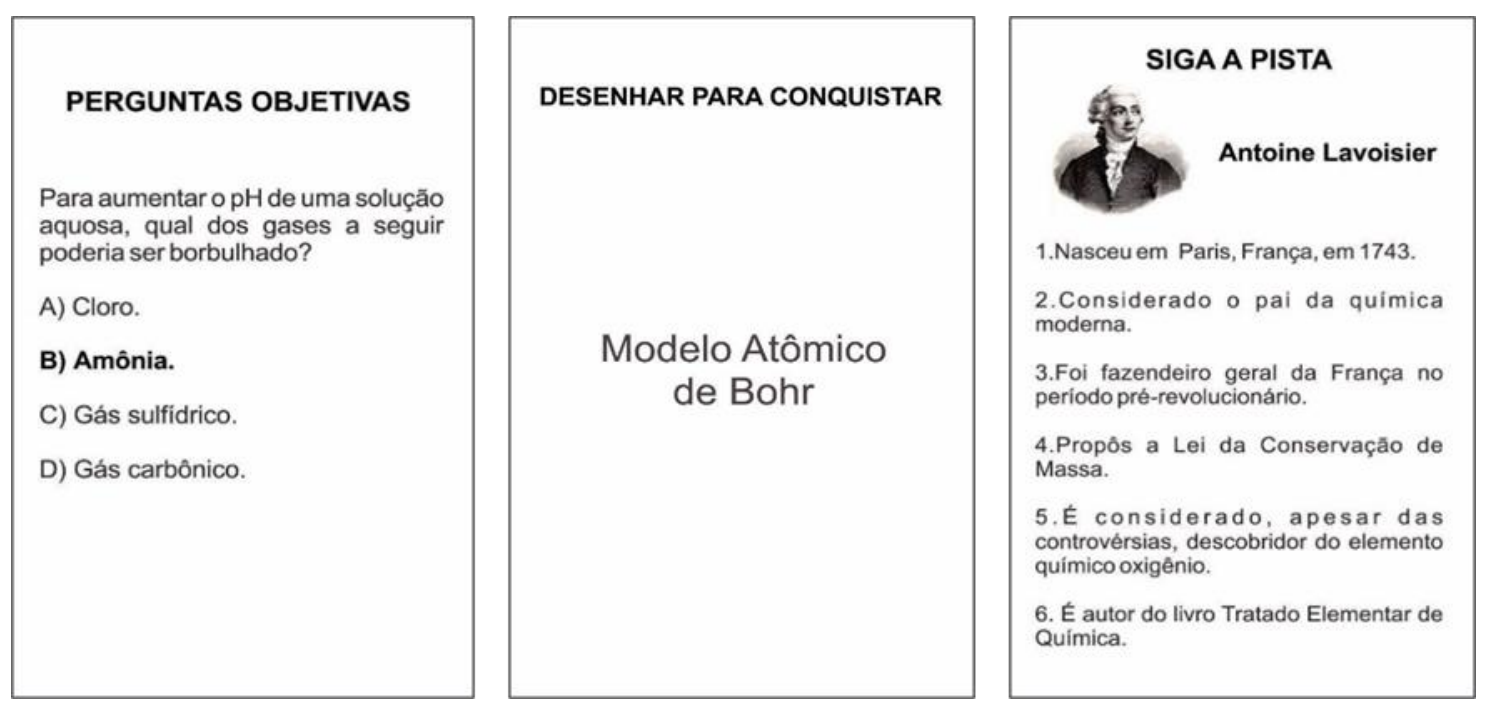

Figura 3 - Exemplos das cartas de desafios - verde ("perguntas objetivas"), azul ("desenhar para conquistar") e amarelas ("siga a pista").

Completam o material do jogo: pinos de quatro cores diferentes, duas ampulhetas, quatro blocos, quatro canetas, quatro discos de impossibilidade de movimento e um dado de seis lados, além do manual de regras. A figura 4 mostra esses elementos complementares:

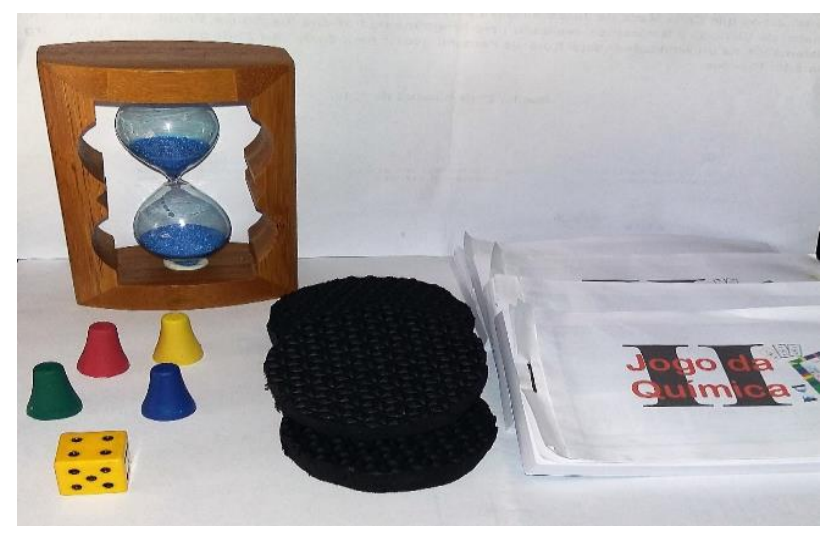

Figura 4 - Outros Componentes do Jogo da Química II.

\section{Aplicação do Jogo da Química II}

O jogo foi bem recebido pelos alunos, que se empenharam em responder as perguntas, discutindo quais seriam as respostas corretas. $\mathrm{O}$ comportamento dos estudantes foi observado durante a aplicação do jogo, para que pudéssemos obter informações que permitissem validar o jogo, de acordo com os critérios estabelecidos para essa pesquisa.

No início da partida, na primeira rodada, surgiram dúvidas que foram esclarecidas pelo professor da disciplina à medida que surgiam. Durante a aplicação do jogo todos os grupos trabalharam de forma conjunta, com todos os licenciandos participando de maneira efetiva, seguindo as regras do jogo, buscando soluções para os desafios. Após o esclarecimento inicial de dúvidas sobre as regras, pudemos inferir que os estudantes compreenderam as regras do jogo, pois o jogo não precisou ser interrompido em nenhum momento para a revisão ou explicação de regras durante a partida.

O potencial didático/educativo do Jogo da Química II pode ser observado durante a aplicação. Os licenciandos foram capazes de relacionar os conceitos e proposições contidas nas cartas do jogo, com o conhecimento que apresentavam, e desta forma, puderam reestruturar seus conhecimentos. 
Em alguns momentos, principalmente nas cartas do tipo "siga a pista", percebemos que algumas características dos conceitos (como a descoberta da radioatividade) ou das personalidades (Rutherford ter sido o descobridor da radiação alfa) foram aprendidas por vários estudantes no momento da aplicação do jogo.

O potencial lúdico do Jogo da Química II também foi observado a partir do comportamento dos estudantes. Sem a intenção de inferir sobre a motivação gerada pela atividade, percebemos elementos como a diversão, o engajamento na vitória e a interação cordial com os colegas de grupo para cumprir as atividades. A competição foi tranquila e saudável, proporcionando uma boa interação e comunicação com as equipes, tornando a participação dos alunos mais atrativa, prazerosa e divertida, já que dividiam tarefas frente aos desafios.

Buscamos realizar observações com relação aos critérios estabelecidos por Novak e Souza (2008), e verificamos bom potencial de interação entre os jogadores, pois todos participaram de forma intensiva, buscando responder os desafios sempre de forma colaborativa. Ainda, entre grupos distintos, observamos que o elemento competição foi bem evidente, todos queriam vencer o jogo. Os integrantes do grupo amarelo, que terminou a partida em último lugar, estavam chateados, verbalizando em diversos momentos a insatisfação com as cartas que puxavam. $O$ jogo não apresentou limitações espaciais e temporais, uma vez que utilizamos apenas uma mesa e cadeiras para jogar e o tempo de aula foi suficiente para aplicação do jogo. Ainda, vale destacar a questão da criatividade (desenhos, mímica) e o elemento desafio, que foi bastante destacado pelos estudantes no jogo, que acharam as tarefas as vezes de fácil execução e outras vezes bastante difíceis.

\section{Análise da Entrevista}

Após a aplicação do jogo foram selecionados quatro alunos, um de cada equipe para entrevista individual, buscando assim conhecer a opinião de cada um com relação a atividade aplicada. A opção por trabalhar com quatro alunos buscou delimitar um conjunto de dados significativos, mas não excessivo, que possibilitasse reconhecer a percepção dos licenciados sobre o Jogo da Química II. Os alunos foram numerados de 1 a 4, sendo alguns dos relatos mais significativos apresentados a seguir.

\section{O que você achou do Jogo da Química II em termos de:}

\section{A) Design}

O aluno 1 afirmou ter gostado do design do tabuleiro, mas apontou sugestões para melhoria, como tabuleiro mais firme, feito em cartão, como nos jogos comerciais. Ainda, destacou positivamente o design das cartas. $\mathrm{O}$ aluno 2 respondeu que gostou das cores e dos discos, que indicam que você ficará uma rodada sem jogar o dado até você acertar a pergunta, classificando a ideia como inovadora e muito interessante, permitindo a articulação entre os diferentes tipos de carta. Por fim, deu uma sugestão relacionado ao disco, a inclusão de uma caveira, para representar punição. Os alunos 3 e 4 destacaram as cores, acrescentando que o Jogo da Química II não repete os padrões da maioria dos jogos de tabuleiro, comerciais e principalmente aqueles que são aplicados em ensino. $\mathrm{O}$ aluno 3 destacou o bom uso das cores e a simetria do tabuleiro: "gosto de coisas simétricas, todo bonitinho $e$ organizadinho... as cartas também" (Aluno 3).

\section{B) Interação entre os Jogadores}

Todos os estudantes entrevistados responderam positivamente com relação a interação proporcionada pelo Jogo da Química II, destacando a boa interação no grupo e também entre os grupos. O aluno 3 destacou que a dinâmica do jogo é boa e divertida, o que contribui para melhoria da interação entre os jogadores: "a cada rodada o grupo precisava de todos, eu e os outros jogadores da equipe, em nenhuma rodada alguém ficava de fora” (Aluno 3). 
As respostas, no geral, destacam a boa interação entre os jogadores no Jogo da Química II e reconhecem que esta é muito importante para facilitar o processo de ensino e aprendizagem. Esse resultado é coerente com a literatura, pois de acordo com Carvalho (2004), a aprendizagem é influenciada positivamente com a utilização de jogos na aula de química, principalmente quando os jogos em grupo proporcionam interação dos alunos com os seus colegas, podendo contribuir, para melhoraria nos relacionamentos.

\section{C) Jogabilidade}

O aluno 1 respondeu que o jogo fluiu bem, não sendo um jogo de difícil compreensão, mas sugeriu diminuir o tempo de resposta para os grupos, o que poderia melhorar a jogabilidade. Essa ideia também foi mencionada pelo aluno 2, em destaque para as cartas azuis, "desenhar para conquistar". Segundo o estudante, o tempo é dilatado, logo, pode "travar" a partida em alguns momentos. O aluno 3 também destacou a boa jogabilidade e o fluxo da partida, sem grandes interrupções, sem muita espera entre os turnos de jogada. Mesmo não gostando de jogos didáticos, o Jogo da Química II chamou sua atenção pelo dinamismo: "Não me sinto atraída por jogos em matéria de ensino, nunca gostei, mas pela forma que o jogo é disposto, como ele é organizado, os desafios que ele traz, me favoreceu porque ele não é monótono como a maioria dos jogos de tabuleiro para ensino são" (Aluno 3). O aluno 4 achou o jogo um pouco difícil em alguns desafios, principalmente quando as cartas tinham temática na história da química, mas elogiou a jogabilidade, destacando a diversão e o pouco intervalo entre as jogadas.

\section{D) Desafio}

O aluno 1 respondeu que o jogo tem muitos desafios bons, podendo promover aprendizagem e rememoração de conhecimentos anteriores: "Sai daquela aula convencional de estar o professor escrevendo, explicando, e fica aquele clima de competitividade. " (Aluno 1). O aluno 2 dá uma resposta mais específica, valorizando os desafios da carta amarela ("siga a pista"): "Achei muito interessante os desafios das cartas amarelas, principalmente as que traziam figuras históricas da química, como os cientistas, é muito diferente as pessoas se ligam a contextos, a cálculos e termos, e acabam não se interessando quem foi que desenvolveu, onde e como. Achei importante na qual até eu não sabia, é interessante" (Aluno 2). O aluno 3 classificou o Jogo da Química II como um bom desafio, porém muito difícil para o Ensino Médio: "Nós, licenciandos, não lembrávamos nomes de alguns cientistas, conceitos, por não ter pago ainda a disciplina história da química... imagina eles" (Aluno 3). O aluno 4 apresentou uma resposta que concorda com a resposta do aluno 2, destacando as cartas do tipo "siga a pista", e acrescentou um comentário sobre as cartas azuis ("desenhar para conquistar"): "Você olhava a carta e pensava, como vou desenhar isso, mais acabou que conseguimos, você lembra... vi isso em algum lugar... então fomos tentando estruturar e juntar uma coisa com a outra. Achei muito interessante essa parte de desenho, é um desafio" (Aluno 4).

Diante das respostas dos alunos, acreditamos que o jogo traz bastante desafios. Durante a aplicação do jogo foi observado que alguns alunos apresentaram dificuldades, principalmente nas cartas que envolvem conhecimentos de história da química, o que pode ser indícios de uma abordagem ahistórica da química escolar (CHASSOT, 1993). Outro desafio citado foi desenhar, destacado pelo aluno 4.

\section{Você acredita que o Jogo da Química II pode ser utilizado para a aprendizagem de conceitos químicos? E revisão? E avaliação?}

Diante das respostas dos quatro alunos entrevistados, pudemos inferir que o Jogo da Química II se configura em uma proposta interessante para aprender alguns conceitos químicos, bem como realizar revisão de conceitos já trabalhados. No entanto, os estudantes entrevistados não parecem ter 
uma boa percepção do jogo como instrumento central em uma estratégia de avaliação da aprendizagem.

O aluno 1 respondeu que utilizaria o Jogo da Química II em sala de aula: "Um exemplo que posso citar é a carta "desenhar para conquistar" (azul), desenhar a ligação metálica... muitos em si se confundem em relação as ligações químicas, acho que o ato de você desenhar a ligação é mais compreensivo do que o próprio conceito, neste caso eu utilizaria. Em relação a revisão também utilizaria, pois acho algo mais descontraído do que você ver aquele conteúdo de novo da mesma forma, então seria uma forma diferente de você rever aquele determinado conteúdo que já foi estudado. Já para avaliação eu não utilizaria, primeiro porque você vai está obtendo ajuda de outras pessoas (equipe), acho que o professor não teria condições de avaliar o aluno se realmente ele aprendeu " (Aluno 1).

O aluno 2 respondeu que na Universidade Federal Rural de Pernambuco, no curso de Licenciatura em Química, só no 6o período é ofertada a disciplina história da química e que esse jogo seria muito útil para iniciar e mostrar o quão importante ela é: "Utilizaria o jogo para uma aula de revisão, pois ele traz muitos conceitos que você precisa realmente pensar e destrinchar, por exemplo no caso da história da química, para iniciar a disciplina e fazer uma sondagem, porque você vai lembrar de conceitos, aprender e tentar lembrar o que você já sabe até aí, estaria dentro de uma revisão. Também faria o uso do Jogo da Química II em termos de avaliação, mas que em partes utilizaria determinados tópicos para determinadas disciplinas, seria interessante restringir as perguntas para determinada área daquela disciplina. Por exemplo, utilizaria para história da química primeiro como uma sondagem no início e final da disciplina e depois como avaliação" (Aluno 2).

O aluno 3 utilizaria em parte como auxílio de aprendizagem para alguns conceitos químicos: "Acho que o Jogo da Química II para revisão seria mais eficaz do que para aprender. Para aprender é necessário que se tenha uma aula, para que você possa solicitar que os alunos leiam e pesquisem para depois fazer o uso do jogo. Em termos de avaliação eu não utilizaria, a não ser que essa avaliação tivesse, por exemplo, avaliar participação e liderança, agora para avaliar conteúdo talvez possa ser usado mas acho que não seria eficaz" (Aluno 3).

O aluno 4 também utilizaria o Jogo da Química II, no entanto, antes da aplicação do jogo deve existir uma aula introdutória: "Faria uso, sim, como revisão, pois seria uma prática para você puxar da memória, lembrar de determinado conteúdo. Na minha visão, jogar um jogo de química com um assunto da disciplina é uma forma de aprendizagem diferente do que da forma tradicional, básica exposição. Vai te ajudar no desempenho de uma avaliação, você não vai tirar nota ruim. Para avaliação utilizaria em parte, porque para aprender poderia ser mais benéfico do que para avaliar" (Aluno 4).

De acordo com análise das respostas, podemos inferir que todos os estudantes percebem um potencial didático do Jogo da Química II para ensinar novos conceitos, mas principalmente para revisão. Também observamos que apenas um dos quatro alunos entrevistados utilizaria o jogo para avaliação, com os demais acreditando que não tem como o professor avaliar as aprendizagens individuais, principalmente quando se trata de um jogo em grupo, na qual você terá ajuda do seu colega de equipe. Tal impedimento na utilização pode estar associado a concepção de avaliação dos licenciandos, ainda muito marcada pela avaliação somativa (ao final do processo), com pouca ênfase a avaliação formativa, a que ocorre durante todo o processo (MEIRIEU, 1998).

\section{Você percebeu alguma limitação espacial/temporal no Jogo da Química II? Se sim, quais?}

Nenhum dos estudantes citou limitações espaciais ou temporais na utilização do Jogo da Química II, no entanto alguns destaques com relação ao tempo de jogo foram colocados: diminuição do tempo das ampulhetas (alunos 1, 2 e 4) e utilização de dois dados para melhorar a dinâmica e velocidade entre os turnos (aluno 2). 
O aluno 3 destacou que, para melhorar a gestão do tempo e evitar limitações temporais, o tempo da ampulheta nas cartas azuis ("desenhar para conquistar") deveria ser contado a partir do momento em que o grupo puxa a carta. Nas regras do jogo, o participante que se prepara para desenhar tem um tempo antes do início da contagem pela ampulheta para entender o comando. A sugestão do aluno 3 é eliminar tal tempo adicional.

\section{Você usaria o Jogo da Química II em sua sala de aula? Se sim, por quais razões?}

Os quatro estudantes entrevistados utilizariam o Jogo da Química II em sua sala de aula. Todos destacaram que a utilização de uma atividade lúdica parece interessante, pois muda a forma padrão em que as aulas de química são apresentadas. $\mathrm{O}$ aluno 2 levantou uma questão interessante: "Utilizaria, pois eu acho que um jogo chama atenção, para química, de uma forma positiva (...), agora, se fosse para utilizar em sala de aula, numa turma de $3^{\circ}$ ano do Ensino Médio da rede pública contendo 50 alunos, seria necessário ampliar o Jogo da Química II" (Aluno 2). Já o aluno 4 destaca que, para utilizar o Jogo da Química II em sala de aula do Ensino Médio é necessário escolher as cartas para que estejam relacionadas ao assunto que está sendo abordado, uma vez que as cartas abordam diversos conteúdos da química escolar. Todos destacaram que o Jogo da Química II é uma excelente proposta para revisões finais, próximas do Exame Nacional do Ensino Médio (ENEM) e outros vestibulares.

\section{Indícios de Validação do Jogo da Química II}

Com base nos critérios descritos na metodologia (NÓVAK e SOUZA, 2008) os resultados quanto a observação de indícios de validação do Jogo da Química II, são apresentados, no quadro o3:

Quadro 3 - Análise dos indícios de validação do Jogo da Química II.

\begin{tabular}{|c|c|c|}
\hline $\begin{array}{l}\text { CRITÉRIO DE } \\
\text { VALIDAÇÃO }\end{array}$ & $\begin{array}{l}\text { VALIDAÇÃO NA APLICAÇÃO DO } \\
\text { JOGO }\end{array}$ & $\begin{array}{l}\text { VALIDAÇÃO PELOS ALUNOS NA } \\
\text { ENTREVISTA }\end{array}$ \\
\hline $\begin{array}{l}\text { Interação entre os } \\
\text { jogadores }\end{array}$ & $\operatorname{SIM}$ & SIM \\
\hline $\begin{array}{l}\text { Dimensão da } \\
\text { aprendizagem }\end{array}$ & SIM & $\begin{array}{l}\text { PARCIAL } \\
\text { (O aluno } 3 \text { acredita que o jogo deve ser } \\
\text { usado apenas para revisão) }\end{array}$ \\
\hline Jogabilidade & SIM & SIM \\
\hline Aplicabilidade & SIM & SIM \\
\hline Poder de desafio & SIM & SIM \\
\hline $\begin{array}{l}\text { Limitação de espaço } \\
\text { e tempo }\end{array}$ & SIM & $\begin{array}{l}\text { PARCIAL } \\
\text { (Os alunos 1, } 2 \text { e } 4 \text { citaram pequenos } \\
\text { problemas de limitação temporal) }\end{array}$ \\
\hline Criatividade & SIM & SIM \\
\hline
\end{tabular}

No quadro 3, percebemos que o Jogo da Química II pode ser validado para todos os critérios apresentados na metodologia, com pequenas observações realizadas pelos alunos nas entrevistas, com relação a dimensão da aprendizagem e limitação temporal. No entanto, podemos pensar que, a partir da observação da dinâmica do jogo e da percepção dos estudantes da licenciatura, o jogo tem potencial para utilização como instrumento integrante de estratégias para o ensino e aprendizagem de conceitos químicos.

Percebemos, na aplicação e também nas respostas à entrevista, que as funções didática e lúdica foram reconhecidas no Jogo da Química II, evitando que seja apenas um jogo ou um material didático, o que mostra que a proposta se configura como um jogo didático para o ensino de conceitos químicos. 


\section{ALGUMAS CONSIDERAÇÕES}

Acreditamos que a utilização do jogo como recurso didático nas aulas de química favorecerá a aprendizagem de conteúdos, como também proporciona motivação e interesse nas aulas e nos assuntos, podendo possibilitar o estímulo à participação, induzindo o aluno a aprender de uma forma prazerosa, num contexto desvinculado da situação de aprendizagem puramente formal e tradicional. Assim, parece importante que os professores busquem metodologias pedagógicas inovadoras, que facilitem a entrada de informações nas aulas de química, não para substituir as aulas tradicionais, mas sim atuar como uma metodologia de apoio ao professor. O aluno pode aprender de diversas maneiras, por isso existem diversos recursos que podem ser utilizados. Os resultados dessa pesquisa são convergentes com as observações encontradas na literatura.

A proposta de elaboração do Jogo da Química II apresentou resultados satisfatórios, pois o jogo elaborado, quando aplicado, obteve resultados positivos em todos os critérios de validação, ou seja, temos indícios de validação a partir dos critérios apresentados.

A partir da aplicação do Jogo da Química II, podemos afirmar que sua utilização em sala de aula contribui não apenas para criar uma alternativa ao modelo tradicional de ensino, mas como também para despertar o interesse do aluno pela química, agindo assim na motivação para a aprendizagem desses conceitos, podendo desenvolver a organização, a autoconfiança, a concentração, a atenção, as competências e habilidades em relação à criatividade, a cooperação e a socialização desses alunos em sala de aula.

Assim, podemos inferir que o Jogo da Química II atingiu os requisitos de um jogo didático para o ensino da química, uma vez que as funções didática e lúdica foram reconhecidas pelos estudantes, o que certamente direcionou a validação da proposta pelos critérios definidos e já discutidos.

O Jogo da Química II foi bem recebido pelos licenciandos, os quais puderam expressar suas opiniões. Esses avaliaram de forma positiva a proposta de atividade lúdica, contribuíram com sugestões para melhoramento do jogo e afirmam que utilizariam a proposta didática em sua sala de aula. Um importante resultado está relacionado a utilização do jogo como instrumento de avaliação. Apesar dos resultados das entrevistas apontarem um possível problema nessa utilização, acreditamos que o jogo tem potencial avaliativo.

Por fim, embora ainda não seja possível disponibilizar na internet o tabuleiro e as cartas do Jogo da Química II, esse pode facilmente ser reproduzido, com modificações nas peças, design do tabuleiro e nas cartas, que podem ter outros desafios, outros temas e outras perguntas.

\section{REFERÊNCIAS}

ALMEIDA, P. N. Educação lúdica: técnicas e jogos pedagógicos. São Paulo: Edições Loyola, 2003.

ALMEIDA, H.C.R.; SIMÕES NETO, J. E. O Jogo da Química - uma proposta de atividade lúdica no ensino médio. In: Anais do XV Encontro Nacional de Ensino de Química, Brasília, 2010.

BRASIL. Parâmetros Curriculares Nacionais. Brasília: Ministério da Educação, 1997.

CARVALHO, A. M. R. Jogos pedagógicos ou a gestão lúdica das necessidades. O Professor, v. 3, n. 87, p. 26-29, 2004 .

CHASSOT, A. I. Catalisando Transformações em Educação. Ijuí-RS: Editora UNIJUÍ, 1993.

CUNHA, M. B. Jogos de química: desenvolvendo habilidades e socializando o grupo. In: Anais do XIII Encontro Nacional de Ensino de Química, Goiânia, 2004.

HUIZINGA, J. Homo ludens: o jogo como elemento de cultura. São Paulo: EDUSP, 2000.

KISHIMOTO, T. M. O jogo e a educação infantil. São Paulo: Pioneira, 1994. 
MACHADO, R. C.; CAVALCANTI, E. L. D. Dificuldades de Aprendizagem versus Desempenho Acadêmico dos Estudantes do Curso de Química: Relatos Possíveis. Revista Debates em Ensino de Química, v. 1, n. 1, p. 4861, 2015 .

MEIRIEU, P. Aprender... sim, mas como? 7 ed. Porto Alegre: Artmed, 1998.

MELO, C. M. R. As atividades lúdicas são fundamentais para subsidiar ao processo de construção do conhecimento. Información filosófica, v.2, n. 1, p. 129, 2005.

NÓVAK, M.; SOUZA, C. E. P. Produção e Aplicação de Jogos Didáticos Para a Aprendizagem de Conteúdos Sobre o Corpo Humano. Disponível em: <http://www.diaadiaeducacao.pr.gov.br/portals/pde/arquivos/3404.pdf>. Acesso em: 10 de fev. 2017.

QUADROS, A. L.; SILVA, D. C.; ANDRADE, F. P.; ALEME, H. G.; OLIVEIRA, S. R.; SILVA, G. F. Ensinar e aprender Química: a percepção dos professores do Ensino Médio. Educar em Revista, n. 4o, p. 159-176, 2011.

SANTANA, E. M. D. A Influência de atividades lúdicas na aprendizagem de conceitos químicos. Universidade de São Paulo, Instituto de Física - Programa de Pós-Graduação Interunidades em Ensino de Ciências, 2006.

SANTANA, E. M. A Influência de atividades lúdicas na aprendizagem de conceitos químicos. In: Anais do I Seminário Nacional de Educação Profissional e Tecnológica, Belo Horizonte, 2008.

SANTOS, S. M. P. O lúdico na formação do Educador. 6a ed. Petrópolis, RJ: Vozes, 1997.

SANTOS, A. O.; SILVA, R. P.; ANDRADE, D.; LIMA, J. P. M. Dificuldades e motivações de aprendizagem em Química de alunos do ensino médio investigadas em ações do (PIBID/UFS/Química). Scientia Plena, v.9, n. 7, p. 1-6, 2013.

SIMÕES NETO, J. E.; SILVA, R. B.; ALVES, C. T. S.; SILVA, J. C. S. Elaboração e Validação de Jogos Didáticos Propostos por Estudantes do Ensino Médio. Revista Debates em Ensino de Química, v. 2, n. 2 (especial), p. 47-54, 2016.

SOARES, M. H. F. B. Jogos e atividades lúdicas no ensino de Química: teoria, métodos e aplicações. In: Anais do XIV Encontro Nacional de Ensino de Química, Curitiba, 2008.

SOARES, M. H. F. B. Jogos e Atividades Lúdicas no Ensino de Química: Uma Discussão Teórica Necessária para Novos Avanços. Revista Debates em Ensino de Química, v.2, n.2. p. 5 -13, 2016.

SOARES, M. H. F. B.; OKUMURA, F.; CAVALHEIRO, T. G. Proposta de um jogo didático para ensino do conceito de equilíbrio químico. Química Nova na Escola, n. 18, p. 13-17, 2003.

Carla Maria de Jesus da Silva: Licenciada em Química pela Universidade Federal Rural de Pernambuco (2016). No Trabalho de conclusão de curso trabalhou com jogos e atividades lúdicas no ensino da química.

E-mail: carlamarykaline@gmail.com

Hiccaro Carlos Rodrigues de Almeida: Estudante de Química Industrial na Universidade Federal de Pernambuco (início em 2013) e ex-estudante da Licenciatura em Química na mesma instituição. Foi bolsista de iniciação científica e integrante do Grupo PET-Química-UFPE. Tem experiência na área de Ensino de Química, com ênfase em jogos didáticos. É professor de escolas particulares e cursos pré-vestibular na região metropolitana do Recife. E-mail: icaro.hc@hotmail.com

Joseane da Conceição Soares da Silva: Licenciada em Química pela Universidade Federal Rural de Pernambuco (UFRPE). Especialista em Docência do Ensino Superior pela Faculdade Frassinetti do Recife (FAFIRE). Mestre em Ensino de Ciências pela Universidade Federal Rural de Pernambuco. Atualmente integrante do Núcleo de Pesquisa em Didática e Conceituação em Ciências (NUPEDICC) e professora de Química na Escola Nossa Senhora da Conceição. E-mail: josilis@hotmail.com

José Euzebio Simões Neto: Licenciado em Química pela UFPE (2005) e mestre e o doutor em Ensino das Ciências no PPGEC/UFRPE (2009 e 2016, respectivamente). Professor no Departamento de Química da UFRPE, vinculado a área de Ensino de Química e professor colaborador no PPGECM (UFPE).

E-mail: euzebiosimoes@gmail.com 